\title{
Interview with Mario Palma on his book: Why INEGI? The Saga of a Mexican Institution in Search of the Truth
}

\author{
Hermann Habermann ${ }^{\mathrm{a}, 1}$ and Mario Palma ${ }^{\mathrm{b}, 2}$ \\ ${ }^{a}$ Former US Chief Statistician and former UNSD Director \\ E-mail: hermannhabermann@aol.com \\ ${ }^{\mathrm{b}}$ Former IAOS President and former member of the Governing Board of INEGI
}

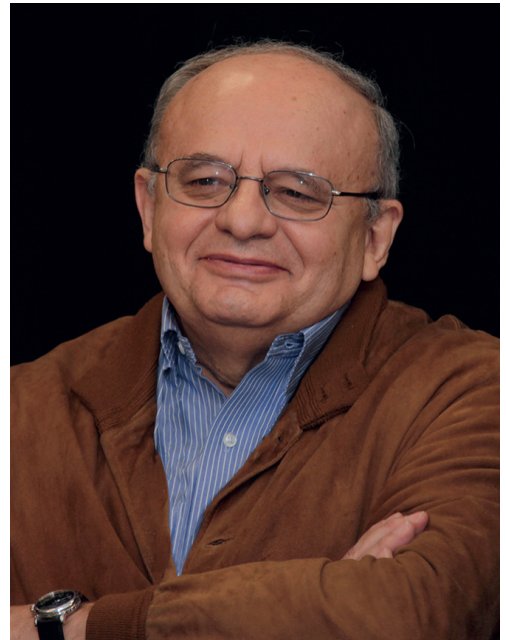

Mario Palma

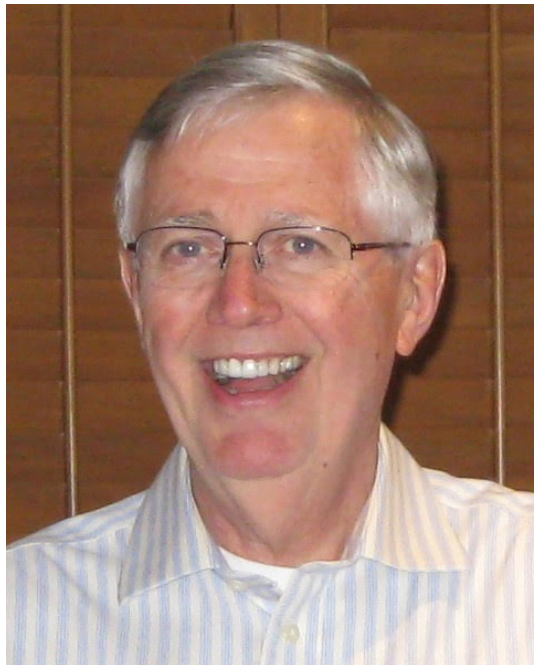

Hermann Habermann

Hermann Habermann interviews Mario Palma on his new book Why INEGI? The Saga of a Mexican Institution in Search of the Truth [1], raising some interesting topics on official statistics. ${ }^{3}$

HH: Good morning. Mario your book comes out at

${ }^{1} \mathrm{HH}$ is the former Deputy Director of the United States Census Bureau, Chief Statistician of the United States and Director of the United Nations Statistics Division. He holds a Ph.D in Statistics from the University of Wisconsin - Madison.

${ }^{2}$ MP is the former President of IAOS (2017-2019), member of the Governing Board of INEGI (2008-2018), Deputy-Minister and Senior Officer in several State Ministries in Mexico. Awarded the Henri Willem Methorst (1995) and Adolphe Quetelet (1999) Medals by the ISI. biased, objective information from National Statistical Offices (NSOs) is a corner stone of official statistics

\footnotetext{
${ }^{3}$ This interview took place through a series of zoom sessions recorded and transcribed by Victoria Bonilla who revised the several drafts with $\mathrm{HH}$ and MP.
} 
it is clear that this is ever more important today. We operate in a time when many statistical offices are under assault from various segments of society. In that sense, although your book focuses on Mexican culture and legal system, it also deals with fundamental messages that are applicable all over the world. And it is those fundamental messages that I think we'd like to emphasise. I would like to start with the title of your book. In your title you use the word "truth". In English, truth is a very big word. It can be a controversial word and people are often suspicious of those who claim to know the truth. In place of logical arguments sometimes people insist on the correctness of their position because they know the "truth" regardless of existing evidence. In what sense do you use the word "truth" in your title?

MP: Good morning, too. It is a very good question, Hermann. Thank you for the opportunity to clarify a bit on this particular terminology. Of course, it is not used in the purely abstract sense. I agree, I would also be suspicious of anyone claiming to know the truth and I don't think any statistical office will claim that either. The objectives are much more humble if you want to use that word. The way I used it was more in the sense that Yuval Noah Harari interprets it in the quote I actually put at the beginning of the book: "the most important secular commitment is to the truth, which is based on observation and evidence rather on mere faith" [2]. This conception of truth I think gets closer to the statistical remit. It is also used in the context of the general public in Mexico, one of the main groups of people the book is addressed to. The principal objective of the book is to explain the role of the National Institute of Statistics and Geography of Mexico (INEGI), which is the role of statistical and geographic public institutions all over the world and how they should produce quality information, as well as why their professional independence has to be preserved. It is definitely used as a contrast or as an opposite to the other extreme that are plain lies, and it is also used in the context of this phenomena, which is happening now in Mexico and all over the world, of the use of fake news and non-methodologically-sound data. That's the sense the book tries to convey, that's why I used this word, but definitely not in the abstract sense.

HH: Two other important and big words that are prominent in your book are "independence" and "autonomy". These are subjects that every national statistics office is concerned with today. The word autonomy is used in many Mexican institutions. There are autonomous universities in Mexico for example. Would you please discuss the breadth and depth of autonomy that you and your colleagues sought and what in fact you achieved? What was it about the situation in Mexico that made this struggle for autonomy so important and how much of this struggle is common to other national statistical offices?

MP: It is a very interesting set of questions. One has to be a bit careful with the use of the terminology and also with what we mean by autonomy, and why we did pursue it. Ultimately, the important thing is that the State has an obligation to provide information to all the public. This is a fundamental universal right actually recognized as such by the United Nations. In the case of statistical information, this obligation is fulfilled by the State through the National Statistical Offices (NSOs). The point would be, and this has to do with the place in society of the NSOs and why we need them, how we achieve this in a way that the public trusts their work. There are, in my opinion, two steps for doing it. One is to undertake the statistical programmes properly, which is to measure correctly through following the proper methodology and the Fundamental Principles of Official Statistics. NSOs have to establish a reputation for doing these things. But then, how do you guarantee against something that is not theoretical, it happens all over the world probably every day and it has happened for centuries, which is the intervention in particular of governments against the public's right to receive information following all these principles. The second very important step is that the public has to perceive that the statistical office is doing its work without the intervention of any other actor that can affect the quality of this information in whatever way, and it could be governments, private actors or any other. That brings us to the situation of how to guarantee the independence of the NSO, which in Mexico has taken the legal term of autonomy.

HH: Let me go back to something you just said. There seems to be a little bit of a paradox. On the one hand, if I heard you correctly, you are saying that the State has an obligation to ensure unbiased, objective information. But now you are saying that the only way to do that, is to make sure that the NSO is independent from the State. So, on the one hand, the State seems to have an obligation but, on the other hand, you are saying but the only way we can do that is to ensure that the National Statistical Office has autonomy from the State. Is that what you are saying?

MP: It is an obligation of the State to provide the information and the official statistical agency will necessarily remain a part of the State. What it is needed is independence from administrative and political processes of the State in relation to other actors of the same 
State. For that you establish a series of checks and balances as you do for the interaction between different powers. All powers -the Judicial, the Legislative and the Executive- are independent between themselves but they are part of the same State. And that's what is meant in this case. They are part of the same State, not of the same executive branch of government, and independent in the technical part from all other powers of the State.

HH: Let's talk about this a little. I don't think you mean that INEGI will be completely independent of the government. So, if they are not completely independent, what kinds of independence?

MP: You are right in qualifying that. I would say complete independence cannot happen in a vacuum. Providing information is a State obligation and the statistical agency is part of the State and the agent with the remit to do it. Complete independence, you cannot go to another planet and be totally out of any influence of any type, specially budgets and that kind of things. The statistical office has to interact with other powers, but this interaction has to be resolved in a way that the law protects its professional independence.

HH: Exactly what kinds of independence were you looking for? And what did you achieve?

MP: Well, the kind of independence we achieved, is what went into the Constitution and into the Law on the National System of Statistical and Geographical Information (LSNIEG). It is a system in which, first, this professional independence and the non-intervention of the Executive and the other powers is established legally. It means that INEGI is not hierarchically dependent on a ministry. INEGI makes most decisions -definitely all of the technical ones, but also many financial and administrative- without having to get the approval of a Minister.

Another feature is that the nomination of the President of the Institute and of the Board of Governors has to pass through a process in which more than one power of the State is involved, in this case the Executive and the Legislative. This is the situation of balances that I mention. An important feature is that INEGI while autonomous, becomes the coordinator of the National System of Statistical and Geographic Information. This means that INEGI interacts and works together with all public institutions that produce statistics (including agencies of the public administration, the Legislative and the Judicial).

The reason we use the word "autonomy", which maybe you can use it as synonym of "independence", is that it is a legal term used in Mexico. It's a purely Mexican thing. There is a reason for the concept. You have to put it in the context of the political history and circumstances of the country, especially during the long period of 70 years in which we had very autocratic regimes in Mexico in the twentieth century. In the 1920's a movement for autonomous universities started to allow selfgovernment in the main public universities against the direct intervention of governments. Not all universities got it, but the main one - the National Autonomous University of Mexico (UNAM), did.

The Mexican political system at the time characterized itself for several things, among them its style which was not the standard autocratic system, some people have called it a "soft dictatorship" some other people have called it a "perfect dictatorship", which are terms that may help to explain its success for so many years, even longer than the Soviet regime in Russia. It was successful at least at the beginning in some economic and political aspects but flawed in the long term. While the system was authoritarian, it worked in very subtle ways, let's put it on those terms. It could occasionally be repressive, but that was exceptional. Things were arranged in a way that pressure and influences were exerted in a discrete but effective manner. In the center of it all was that the President of the country who concentrated an extreme amount of power.

The democratization process in Mexico, which took a long time but mostly was concentrated in the 1990's and the beginning of 2000s, prioritised the need for balancing this power by separating some important functions from the sphere of the Executive branch. One consequence of this is that several institutions became autonomous under Mexican Law. The first of them was the Central Bank of Mexico, another was the Electoral Institute that used to be headed by the Minister of the Interior -who belonged always to the party in power-. So, you can imagine the situation when people complained about the legality and fairness of elections and that sort of things. Another example was the Human Rights Commission, and then INEGI as the provider of information to the public and all actors in society.

HH: I would like to pose a hypothetical situation. We have all seen situations where the political leadership is perhaps not interested in discovering, for example, the depth of poverty for particular minority groups. And so, the President might suggest to the head of the statistics office that maybe they did not need to perform a particular survey or did not need to oversample in a particular study. What would prevent that kind of activity under what you and your colleagues have done in Mexico? What would prevent the President from having an unofficial phone call with the head of INEGI 
to accomplish the actions I have described. What are the limits for independence and autonomy in practice?

MP: Ok, well. It's a very good hypothetical question and I am very glad not to have received that kind of call almost never in my life. There was one, but not really so clear and not from a President which is subtly narrated in the book and it involves the then head of national security. But this hypothetical situation, to stop someone from doing something, well it would be difficult. The thing is to stop someone from get something out of such an attempt. Maybe just to have the law and the reputation helps for anyone to think twice before doing it, but it is not guaranteed it will not happen as we have seen all kinds of Presidents, even in very democratic countries, not hesitating on trying to interfere in the work of the NSO. What protects from that? INEGI has an Annual Working Programme which is written with a previous consensus on it, in which practically all government ministries participate. Actually, the final approval of the Annual Programme is not a decision by the President of INEGI but by the Board of Governors and in it there are all the statistical projects that are to be carried out in the year. The programme is published in the Official Gazette of the Federation and becomes obligatory for all administrative units of the State. The continuity of the statistical projects is established through this Annual Programme accordingly to the statistical needs of the country.

And something very important, there is a calendar for the publication of the results of the statistical programmes which is published and made available to all the public in advance every year and it can only be modified by the Board of Governors. But any modifications have to be discussed and there has to be a very good reason for any change, which again has to be informed to the public months in advance. It's a calendar which is established and there is a responsibility for the officials at INEGI to fulfill it.

Besides there is a final barrier of protection to the Institute's work and that is all the people who work on each statistical project. They are well aware of the methodology and the data, and especially of what I have called the ethos or the prevailing philosophy of the institution. All of them may have affinities or not with different political parties and they are the final auditors of what is done.

HH: If I understand correctly then, you have transparency of your programme of work in that INEGI has a yearly calendar of what is going to be done. If anything is changed that will be transparent to all. All your programme is available for public inspection. More than this, if I understand correctly, not only the technical decisions on how surveys are operated but also the content of your programme - which surveys are to be fielded is within the scope of INEGI's authority. Do I understand this correctly?

MP: Yes, it works in two ways really within INEGI. The actual approval and big revisions of programmes belongs in the field of the Board of Governors. The president of INEGI is both the Head of the Board of Governors, but also the administrative head of INEGI. That means that the Board of Governors is separated from the actual work. Once a survey or a census is undertaken, their results -different to Central Bankswon't be taken for discussion to the Board of Governors. That doesn't happen. In an independent Central Bank, there is a discussion there of the interest rates for example and there would be opinions. In this case, it works in completely technical way and the results are published under the responsibility of the president of INEGI. They won't pass to any type of consultation to the Board of Governors. It's a responsibility of the President, as head of all the technical people who developed the programme. That's how it works according to the Law.

HH: In your book you have an interesting section on the crime statistics programme and the role that independence played in undertaking that survey. Perhaps you could discuss what INEGI did with respect to the crime statistics programme and how it used its independence in that area.

MP: The crime statistics programme was the first big new programme initiated in 2009 just after autonomy was officially declared and that's an interesting thing. The programme developed from the security situation that the country was suffering at the time, even if we had had some high levels of criminality before, this was an unprecedented crime wave, and it was obvious that we didn't have good information. A decision was taken to create a new subsystem of information: the Subsystem of Government, Public Security and Justice Statistics. There were before a few statistics on these subjects collected from Public Attorney's Offices and from legal courts but obviously insufficient. Now the Subsystem has several surveys (on victimization, corruption, police forces, etc.) and censuses (on government, prosecution, human rights, transparency, judicial statistics, etc.), but the programme that was really the key for the development of the Subsystem, and I would say became the reference to it was the National Survey on Victimization and Perception of Public Safety, which we developed with the help of the United Nations Office on Drugs and 
Crime (UNODC), our friend Angela $\mathrm{Me}^{4}$ and her team there helped us a lot because we really had to learn a few things on crime and victimization measurement. Actually, some of them no other country knew at the time, only UNODC could be a source of know-how. From then on, we started to develop together some new projects like a joint Center of Excellence for Statistical Information on Government, Public Security, Victimization and Justice; the promotion of the International Classification of Crime for Statistical Purposes (approved by the United Nations Statistical Commission - UNSC) and of two roadmaps, one for Improving Crime Statistics at the National and International Level (unanimously endorsed by the UNSC and the UN Commission on Crime Prevention and Criminal Justice) and a second one to Improve Drug Statistics (also adopted by the UNSC and in this case the UN Commission on Narcotic Drugs), among other projects.

This is an interesting case because it demonstrates independence working in a real situation, in a very sensitive subject for the country because of what was happening. We had a criminal wave, but we didn't know exactly what was happening and governments, especially state governments were very touchy on the subject. Previously, there was in particular one private survey that had a history of trying to measure crime with the characteristic that they were fond of ranking the states as to which ones had the worst criminal problem. This was touchy just because it happened, but it is really something that experience has shown us it is not advisable to do because of the impossibility to compare different crimes across different situations and populations. There are states in Mexico characterized for high homicides rates and drug activities where the incidence of kidnappings, extortions and petty crime are very low. This happens when a very powerful criminal organization in a state restrains from other crimes to avoid unnecessary attention to its main (drug related) activities. But you can also have the opposite, there are places with a high rate of spare-car-parts stealing and other petty crimes which may amount to a lot in total numbers, while having a low incidence of homicides. That is why is not advisable to make this kind of comparisons. It provoked that each time the results of this private survey were published the state governors and the federal government really reacted in a very bad way,

\footnotetext{
${ }^{4}$ Angela Me is Chief of the Research and Trend Analysis Branch at the United Nations Office on Drugs and Crime (UNODC) where she oversees global, regional and national research in the areas of drugs and crime.
}

they didn't accept the information which was actually having the wrong effect in the sense that it was not used and only triggered political reactions.

At the time when we decided to develop a comprehensive victimization survey, I would say people in the government were obviously afraid of what was to come out from INEGI while the people who were doing the private survey were vocally suspicious that INEGI may even help the governments with the figures. That brought even a discussion in the press but in the end the INEGI survey was accepted by the Federal and state governments as the point of reference. When the results came of the first survey, a thing that would be ironic, were it not so tragic, happened. The results showed double the amount of crime than the ones published in the private survey. That took care of the worries of the people behind the private survey. INEGI came with results that were not nice to the ears of any government but were accepted because of the quality of the information that it was informed to them, and one particular aspect, we didn't rank them. I think that really helped. It was not a question of attacking the government, it was a question of providing information for the governments' policies. So they could do things that they were not doing before from statistics they trusted.

HH: If I understand what you are saying, INEGI saw an information gap in the way information about crime was being developed and presented and INEGI made the decision to close that gap in a highly technical and professional way. Suppose we look at the situation from a different angle. Let me suggest to you none of the officials at INEGI are elected. Where does INEGI get the authority and mandate to decide for the country what information gaps are necessary to be filled. Should not this be the province of elected officials to decide what information is needed or not needed? Is this decision that INEGI took on crime statistics an example of the tension that can develop between an autonomous national statistical office and the elected officials? INEGI saw an information gap and decided that this needed to be filled. INEGI is appointed, they are not elected, they have no apparent mandate from the public to develop better crime statistics. How does INEGI ensure that is not usurping the province of the elected officials? How does INEGI ensure that it obtains the input of elected officials in a way that doesn't compromise INEGI's independence?

MP: Yes, that's a very good point. That's very important and something I have mentioned before, becoming independent doesn't mean you are not going to deal with the government and that there will necessarily be 
confrontations. It really means you are going to work with the government very closely. Actually, legally INEGI became the coordinator of the National System of Statistical and Geographic Information. There is a structure which is arranged in a way that elected and non-elected officials participate in the decisions, besides private sector and users from the academia. It is a system that works in different levels besides the consultation to all the public -which includes governmentsfor each particularly big survey or census. In the legal structure of how INEGI works there are three levels of councils of consultation for the participation of people from outside the Institute. The most important one is the National Consultative Council which is formed by the president of INEGI and representatives from each ministry of the Federal Public Administration, the Judicial Power, the Chambers of Deputies and Senators, besides five representatives from state governments. It also includes a representative from the Central Bank and other public institutions. Among its functions, all the programmes of INEGI have to be presented to them and they have the power to give opinions on them, as well as they can propose subjects, themes, surveys and indicators to be used.

There are two other levels of formal external participation. Besides government and crime, there are three other subsystems of information: Demographic statistics, Economic statistics, and Geography. Each one has several Specialized Technical Committees, normally chaired by the federal public institution in charge of a subject or its main user. Here is where new programmes are examined, needs and proposals by all government agencies are presented, changes to methodology are discussed. There are 58 of these committees. At the next level, within each subsystem there is an Executive Committee that discusses the results of the Specialized Technical Committees and in turn is a channel to bring subjects to the Board of Governors and the National Consultative Council. That's how the consultative system works.

HH: What I am hearing is that you and your colleagues recognized the importance of not confusing independence with arrogance. To ensure that the decisions made by INEGI were done in a consultative manner you created a network of committees and institutions that consulted with INEGI and participated in the decisions. Would it be correct to say that by listening to this network INEGI provides legitimacy for the types of decisions that we have been discussing here. While INEGI did have technical independence and certain levels of budgetary and administrative independence you recognized that without the support and without the network that you built, your mandate could disappear rather quickly. Is that a fair statement?

MP: Yes, it is. I would even add something, if a statistical or geographic agency wants to get a budget it first has to show the people in charge of deciding the budgets that what they provide is a good product for them, that they can use it for themselves. I would say that's the best recipe for a budget negotiation, now or in the future. That's the part the statistical office has to work on its own: quality of statistics, but their usefulness has to be transmitted to the people in power.

HH: Let us continue with our discussion with the concept of independence and autonomy. As we have discussed, I believe INEGI has a much broader concept of independence than just technical independence. Some would suggest that if the State can grant autonomy and independence it can take them away. In the final analysis the State still has final control. However, while the INEGI of today may not be completely autonomous, it possesses measures of decision making which are significantly more extensive than in most national statistical offices.

MP: What it was achieved in the case of INEGI's autonomy is a solid governance system that provides the institution with instruments to undertake its work based on technical considerations with a good margin of freedom as to administrative and/or political constraints. Certainly any legislative process can be reversed, but as this governance system is the result of a constitutional reform that to be changed will require a qualified majority in both Chambers of Congress, the political consequences of doing it or attempting to do it provide a good barrier of contention. This is the advantage of being guaranteed by a legal and institutional framework at the constitutional level.

We in Mexico use the term of autonomy, first, because it is used in the legal system. Secondly, we were in the middle of a process of democratization that was seen as such both by the people in power and by the opposition. The latter included INEGI's autonomy as an item in its democratization agenda.

HH: In your book you describe how, at the same time you and your colleagues were thinking of transforming INEGI into an autonomous institution you experienced an earthquake that destroyed your office with a tragic loss of lives. As a result, you had to move the entire office to another town and build a completely new physical office while you were trying to construct this autonomous institution. Could you discuss the impact the earthquake and the physical movement of the office had and how these challenges were overcome? 
MP: It was part of the problems, but it was part of the solutions too. At the beginning, as I said we had the challenges of any new institution. We didn't have the ideal budgets for sure, but we started. The president at the time was Pedro Aspe who implemented the first measures. One important step was to establish regional and, in each state, local offices of INEGI which was something that didn't previously exist and their absence meant that the national population census in particular or the big surveys depended on the help of the local governments or other federal institutions, like the Ministry of Education to recruit teachers to carry out censuses. That really was a problem for INEGI as the quality and completeness of the technical work didn't depend on its own resources. This problem was one of the first aspects to be addressed and it was approached in a way that was different from the normal way of managing things for the states' governments when they dealt with the federal government. Normally, what particularly happened when one party dominated federal and the local governments, was that the delegates or the representatives of the federal government were actually people from the team of the local governor who considered them as part of his hierarchical structure. INEGI broke on that with a scheme that made them representatives to the region and not to the state. In this way nominations were kept completely professional.

Then this big earthquake that you mentioned occurred. The earthquake was something catastrophic for the country in general and for Mexico City in particular. In the case of INEGI we lost completely one building with the loss of lives and another building was severely damaged and unable to be used. So, we had no choice but to move. There were not places to rent in Mexico City because it was not only us who had suffered losses. More than ten thousand people were killed and many buildings destroyed. There was not much option to discuss about going out of Mexico City, the problem was to find where and the conditions, and I tell the story in the book. Finally, we were very fortunate to find a local government in Aguascalientes that was very helpful and we moved there. And that brought many advantages in physical infrastructure and social conditions for our workers. Among them, it put the central offices of INEGI outside the capital and the center of power in Mexico, being the biggest public institution ever to move out of the city. Also from the human point of view, we had to move 3,000 families to Aguascalientes and that meant building new houses and providing credits for buying them, besides lots of other things, even schools had to be built. At the same time it created what you would call esprit de corps, people suffering many problems together in a new environment and working together to solve them. At the same time INEGI was building against all these complications its reputation in the country, but specially in government, undertaking three national censuses (economic, population and agricultural). That was crucial because in the end became the most important factor to get the funds for the future and to improve the institutional capacity to be able to start new projects.

I would also say that we were very fortunate that in those years (late 1980's and early 1990's) there were at least two Presidents of the country that understood the importance of statistics and several influential ministers who were very supportive of the Institute's work, one was a former president of INEGI, Pedro Aspe -by then Minister of Finance-, and that really helped as we had something to sell, but at the same time we had somebody to listen to us and with a good disposition to give us the necessary budgets.

And then INEGI was asked to participate in projects that were not typical statistical or geographic. This is when the Institution had established a reputation for the quality of its work and its capacity to organize national field operations. The first one was the measurement of all the land plots in the country for the 1992 Agrarian Reform that was one of the largest programmes of land privatization in the world ever, in which the Institute was responsible for measuring and producing almost 9 million maps. In 1995, INEGI was also invited to coordinate the new National Development Plan, which involved the organisation of forums throughout the country with all sectors of society; the coordination with all ministries and agencies of the Federal Public Administration, the Legislative and Judicial powers, the state governments and the private sector; the compilation of proposals and the final drafting of the plan.

HH: It is usual in a bureaucracy that whenever one wants to make substantial changes, opposition may appear from many different quarters. You mention in your book that such opposition did in fact occur. How did you win over their opposition?

MP: That was not easy really because even if I have said that at the very top we had a friendly reception to most of our ideas and programmes, there were many bureaucrats in the middle and a few in relatively high places that were against it. That's why, even if the idea of autonomy had approval at the very highest places, it took still sixteen years to get it which is more or less a long time. I would say the forces against it were sometimes only the typical bureaucratic oppositions to 
new proposals to change paradigms that have been there for a long time. But then, there was political opposition due, in my opinion, to the fear of losing control over the area of official statistics. A funny thing happened and I mention it in the book. Normally when a political party was in power, they would find ways not to promote the autonomy subject while the opposition would like it; and when these people in power changed and became opposition they started liking the idea and so on. In the end, there was a moment of consensus among all the opposition in the Legislative that was joined by the political party in power when autonomy was finally approved in 2006.

HH: What if anything, as you look back, would have done differently? There was a sixteen-year process to create an autonomous INEGI and what, if anything, do you think should have been done differently?

MP: I wasn't the whole time in the process. Of these sixteen years, quite a few of them I was not at INEGI but I followed the whole process. I was very glad to return to INEGI after autonomy was obtained and being able to help in its implementation. You may be surprised about what I'm going to tell you, but if I had known better the many options and subtleties of this political system even when it became democratic, I would have been even more careful of some aspects of autonomy and especially how it works. Because the balances are there, as I mentioned, between the Executive and the Legislative and the two of them are in different roles taking decisions on a particular matter (for instance in nominations to INEGI's Board of Governors), but this doesn't work so clear when the same political party that is in the Executive dominates the Legislative. I am not talking of any particular regime; it happens in more than one. There is not a clear way of avoiding a situation of this type, I mention in the book one instance in Mexico in which other autonomous institutions (among them INEGI) participate, along with the Executive and the Legislative, in the selection process of nominees for another autonomous institution. Further analysis is needed on the implementation of mechanisms such as this.

HH: The development of the Fundamental Principles of Official Statistics is considered by many to be the most important international effort to support national statistical offices. Interestingly enough, although they are implied in several of the principles, independence and autonomy are not explicitly mentioned in the Fundamental Principles. Your book, in a very readable way, gives an authoritative view of the struggles that ensued to obtain an autonomous institution. My question is, did the Fundamental Principles, in any way, play a role during this process? Did you depend upon them? Did you use them to convince people? Were they effective or just a kind of window dressing?

MP: I think they were very helpful in the argument for independence in general. I must tell you that the very first drafts of the future Law (LSNIEG) included in order the ten Fundamental Principles as they were approved in 1994. Intentionally, we took care of putting them as they were presented at the United Nations. They helped to build the fundamentals for the discussion. And because if you think of it, besides the implied mention of independence, what the Principles are saying is how you provide this information properly to society. It is really the objective of the Principles, to have something agreed internationally for this purpose, and that's why we put them there. In the final version of the Law, even though they are not listed in the same order as in the UN document, all of them are there.

In relation to the subject of independence what the Fundamental Principles do is to establish that statistical agencies have to act accordingly to strictly professional considerations and that this has to be guaranteed by legal and institutional frameworks and respected at all political levels. In this sense, they are addressed both to statistical agencies and to all State powers. And in this way they were approved unanimously by all countries represented at the United Nations in the General Assembly in 2014.This is the basis for the concept of professional independence. What we did in Mexico was to take it to the highest possible level, according to our legal system, in what we call "autonomy".

HH: In building strong independent offices how important is building international networks and how does one build these international networks? How important are institutions like the United Nations Statistical Commission and others such as the IAOS?

MP: I would say it's very important. Some people I have met in Mexico and in some other countries don't believe it, and they think to engage on international relations is a waste of time and money. I would say it's just the opposite. It's as important maybe as the internal network. Why? For several reasons and some are technical, and some are political. Technical, it's easy to see, I mean both statistics and geography are very dynamic disciplines that are moving all the time with technology, with new developments and methodologies. It's not something static and the only way to keep abreast of developments is to be part of an international network and participate in the discussions wherever they take place, I mean the ISI, the IAOS, the United Nations, the 
OECD of course, UNODC in the case crime. For instance, we couldn't have developed the crime system of information in Mexico without the help of the UNODC. You know very well, on censuses there is a permanent discussion on how they should be undertaken, and surveys of course, geography is almost purely technical and developments go by the day. And that's a fact on the technical side, but also on the political side. The international multilateral forums are important and also the bilateral relations, and each country will need some. I mention in the book all the bilateral programmes that we had with the United States, and then with Canada. The world-multilateral is crucial too for technical reasons and also for political ones. The "union" of all the countries working in statistics is very important even to protest against the injustices exerted against a statistical office or a statistical director in countries that I may not mention the names in polite company. But there are also many other aspects which takes me to the next point: the future of statistics.

One issue is already becoming quite clear and that is the role of and the relationship with the big transnational producers of information, all these big companies that are powers in themselves and that produce statistics. It's not only the political side that will have to be regulated by governments at some points, but the role of statistical agencies in the future will have to be addressed. Personally, I don't see a way this can be solved bilateral or unilaterally by any one country. This is something that, even for the most powerful countries, will need an international agreement, preceded by necessity by an international conference. This may be a novelty as it could be the first big international convention that will have to include countries and the private sector. And for that conference and negotiation, I would say the statistical profession -official and non-officialhas the potential to play an important role in which the key player could be the United Nations Statistical Commission.

HH: Let us continue to talk about the future. Where does INEGI go now? How secure are the gains that have been made over the years? How secure are the networks which I believe provide, the transparency? What are going to be the big problems that INEGI is going to have to look at in the next three, four or five years?

MP: Well, it's this kind of battle that will never end and you can never say we have secured the future. Of course, what's to be done in the future? I would say it's practically some of the same things that we are now doing. INEGI will have to keep measuring properly and maintain its reputation. It will have to keep providing a service to the country and to the public administration that they value as useful. Those are the main points, but still one has to negotiate budgets. This must be done with a vision of the challenges coming and some are very clear. As I mentioned before it is already clear that the future will have a discussion on the role of the statistical offices and the role of other producers of statistics and INEGI will have to be prepared and to establish a role for the future for the institution, that's one important challenge.

Another one will come from the fact that there will always be a technological revolution going on and that will be costly. This is something that will require from the Institution lots of efforts and resources, among them expensive technologies and equipment, as well as talented people who would still need to be trained and paid accordingly. NSOs will have to plan sometimes years in advance and would require a permanent effort. It will be one of their main challenges, really.

HH: Mario you will have the last word but I would like to thank you for participating in this question and answer session about your book. I would also like to thank you for writing the book. It shows us how a national statistical office can be transformed into a major institution in its country with far reaching levels of independent decision making. The book provides us the opportunity to ponder important concepts like autonomy and independence: what they mean and how far an NSO can go in obtaining them.

MP: Many thanks, Hermann. Writing this book on the history of INEGI brought of necessity a revisiting of practically the whole range of topics related to official statistics, which in one way or another are common to all official statistical agencies worldwide. I would like to thank you for your time and help in sharing these thoughts with the international statistical community. I highly appreciate it.

\section{References}

[1] Palma M. Why INEGI? The Saga of a Mexican Institution in Search of the Truth. Mexico: INEGI; 2021. Free download in: https://www.inegi.org.mx/app/biblioteca/ficha.html?upc=8894 63835592. Also available in Spanish.

[2] Harari YN. Sapiens. De animales a dioses. Una breve historia de la humanidad. Translation by Joandomènec Ros. Madrid: Debate; 2014. 